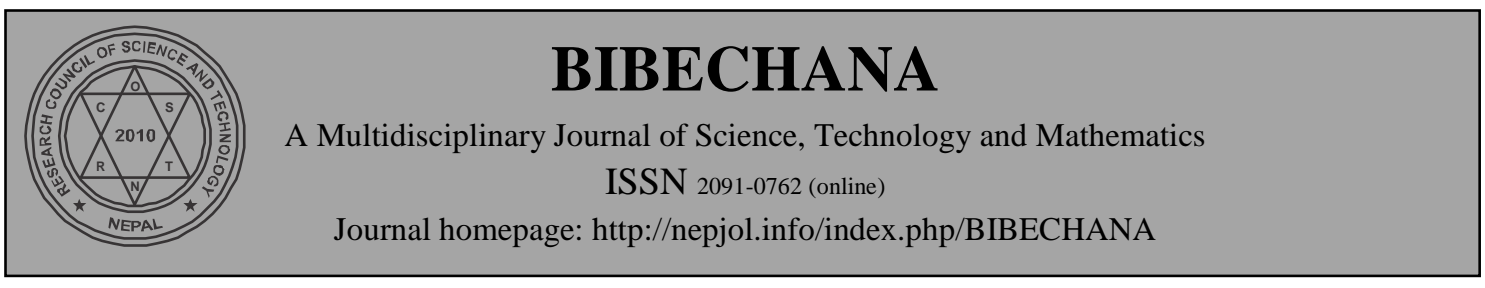

\title{
UV-vis investigation of (CTC/Orthodox/Green) tea in presence of Brij 35/Water system
}

\author{
Ajaya Bhattarai ${ }^{1 *}$, Jay Narayan Mitruka ${ }^{2}$, Subas Kumar Chapagain ${ }^{2}$, Prem Kumar Shrestha ${ }^{2}$ \\ ${ }^{1}$ Department of Chemistry, M.M.A.M. Campus, Tribhuvan University, Biratnagar, Nepal \\ ${ }^{2}$ Department of Chemistry, Mechi Multiple Campus, Tribhuvan University, Bhadrapur, Nepal \\ *Corresponding author: bkajaya@yahoo.com
}

Accepted for publication: February 04, 2014

\begin{abstract}
The precise measurements of (CTC/Orthodox/Green) Tea absorbance in presence of Brij 35/Water system at room temperature by UV-vis technique are reported. The concentrations of Brij 35 [Polyoxyethylene lauryl ether] were varied from 0.01 to $0.02 \mathrm{~mol} / \mathrm{lt}$. Tea concentration in quvette during UV-vis spectrum registration was the same. Obtained results showed a noticeable decreasing of Tea absorbance as a function of Brij 35 concentration. There is evidence of Tea absorbance in the following order: Orthodox $>$ CTC $>$ Green.
\end{abstract}

(C) 2014 RCOST: All rights reserved.

Keywords: CTC tea; Orthodox tea; Green tea; Brij 35; Water; UV-vis.

\section{Introduction}

Nonionic surfactants are surface-active compounds that are non-ionizable in aqueous solutions that consist of a lipophilic part (e.g., alkylated phenols, fatty acids, long-chain linear alcohols) and a hydrophilic part (primarily ethylene oxide chains of various lengths). These compounds are second in worldwide surfactant consumption, comprising $35 \%$ of the total surfactant market.

The most interesting, commercially-available nonionic surfactants are ethoxylated nonionic surfactants (EONS). The analytical grade EONS are Octylphenol decaethylene glycol ether(Triton X-100) and Polyethylene glycol(23)lauryl ether (Brij 35) [1].

Brij 35 is also called Polyoxyethylene lauryl ether is one of the nonionic surfactants widely used both in biochemical and chemical processes for its virtues such as high stability, well-dissolved, and easily mixing with other typical surfactants for a mixed use [2].

Studies indicate that Brij 35 [3] acts as a surfactant in Micellar electrokinetic chromatography (MEKC). It is known that Brij 35 [4] is also beneficial in UV monitoring of solubilized proteins due to their low UV absorbance. This compound is useful in slowing down electro osmotic pumping, which allows users to change $\mathrm{pH}$ values without drastically altering the flow rate. The critical micelle concentration of Brij 35 in water is $0.0001 \mathrm{~mol} / \mathrm{lt}$ at room temperature where as in D20 is $0.00011 \pm 0.00002 \mathrm{~mol} / \mathrm{lt}$ [5] and structural formula of Brij 35 is given in Fig. 1.

After water, tea is the most widely consumed beverage in the world [6]. It has a cooling, slightly bitter, and astringent flavour that many people enjoy [7]. Tea originated in China as a medicinal drink [8]. Two types of tea are manufactured in the factory: Orthodox and CTC. 


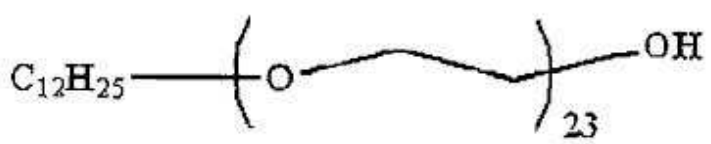

Figure 1: Structural formula for Brij 35.

Orthodox tea refers to the process, where the tea is hand-processed or by rolling it in the machines. In Nepal, orthodox tea is produced and processed in the mountainous regions of Nepal at an altitude ranging from 3,000 - 7,000 feet above the sea level. There are six major districts, primarily in the eastern regions of Nepal that are known for producing quality orthodox tea, which are Ilam, Panchthar, Dhankuta, Terhathum, Sindhulpalchok and Kaski.

Crush tear curl (CTC) tea is a method of processing tea, where three main steps are involved - crush, tear and curl, hence the name CTC tea. CTC tea is produced in lower altitudes in the fertile plains of Nepal, which are warm and humid, primarily in the Jhapa district, which is ideal for the production and processing of CTC tea.

The handmade tea or green tea is prepared by drying green tea leaves and crushing with the help of hands. It is especially found in Darjeeling, India.

Recent studies suggest that green tea may help reduce the risk of cardiovascular disease and some forms of cancer, promote oral health, reduce blood pressure, help with weight control, improve antibacterial and antivirasic activity, provide protection from solar ultraviolet light [ 9].

Our research is focused on the surfactant and tea interaction. UV-vis technique is very useful technique to see the effects of tea on surfactant. There is lack of information about Tea / Brij 35/water systems.

The aim of the present work is to analyze the influence of concentrations to Brij 35 by UV-vis method at room temperature with (CTC/Orthodox/Green) Tea in water.

\section{Experimental Section}

Brij 35 was from Sigma-Aldrich Steinheim, Germany, and was dried under vacuum at $25^{\circ} \mathrm{C}$, CTC tea was from Jhapa, Nepal, Orthodox tea was from Ilam, Nepal and Green tea was from Darjeeling, India. The investigated solutions were prepared gravimetrically at room temperature by dissolving $500 \mathrm{mg}$ each tea in $20 \mathrm{ml}$ of doubled distilled water and used after 5 days for the experiments. Brij 35 solution with concentration $0.02 \mathrm{~mol} / \mathrm{lt}$ was used as stock solution.

UV-vis measurements were realized with the following procedure. Before each measurement base line was registered for suitable Brij 35/ water and afterwards a Tea solution in the same solvent was added. After adding Tea solution to the Brij 35 once the whole liquid volume was stirred very carefully. The absorption band was registered as a function of Brij 35 concentration. We also investigated the absorbance change of (CTC/Orthodox/Green)Tea with water on Double beam UV-Vis spectrophotometer (LT-2900 model), India.

\section{Results and Discussion}

\subsection{Absorption spectra of Orthodox tea / CTC tea / Green tea}

The absorption spectra of Orthodox tea show the highest absorbance value in comparison with CTC tea and Green tea. The absorbance value is higher in CTC tea than Green tea below 500nm but after that it was found the higher value of absorbance of Green tea in comparison with CTC tea. The absorption spectra were shown up to $600 \mathrm{~nm}$ (Fig.2). 


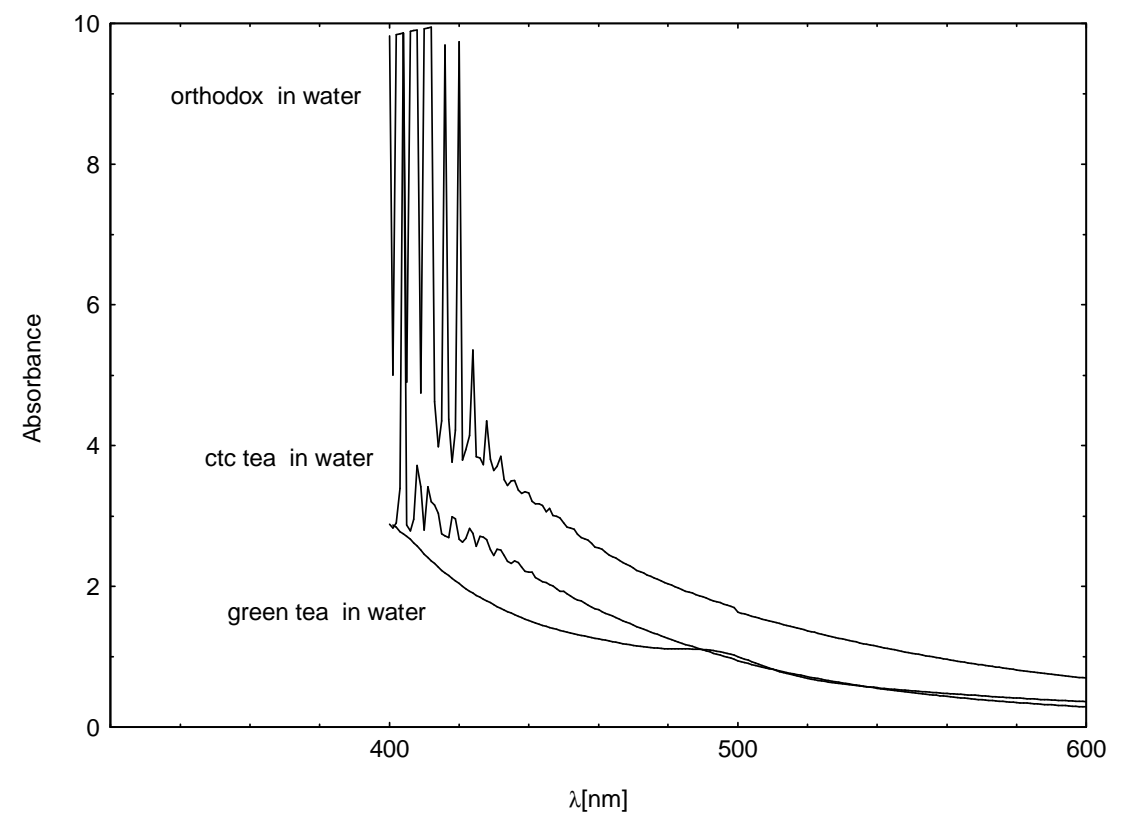

Figure 2: Absorption spectra for Orthodox tea in water (top graph), CTC tea (middle graph) and Green tea (bottom graph).

\subsection{Absorption spectra of Orthodox tea / CTC tea / Green tea in presence of Brij 35}

The absorption spectra of Orthodox tea, CTC tea and Green tea in presence of Brij 35 show the absorbance value within the range of $300 \mathrm{~nm}$ to $600 \mathrm{~nm}$ (fig.3). The absorbance value of Brij 35 is the highest in Orthodox tea, and then lower in CTC tea and the lowest in Green tea. Moreover, depending on Brij 35, a small shift of the maxima into a longer wave length (red shift) has been noticed in the following order: Green tea $>$ CTC tea $>$ Orthodox tea.

\subsection{Absorbance of Green tea in absence and presence of Brij 35}

The absorption band of Green tea observed to be the highest in absence of Brij 35 and then the absorption band decreases with the presence of Brij 35 and further decreases when the concentration of Brij 35 increases (Fig.4).

\subsection{Absorbance of CTC tea in absence and presence of Brij 35}

The absorption band of CTC tea observed to be the highest in absence of Brij 35 and then the absorption band decreases with the presence of Brij 35 and further decreases when the concentration of Brij 35 increases (Fig.5).

\subsection{Absorbance of Orthodex tea in absence and presence of Brij 35}

The absorption band of Orthodex tea observed to be the highest in absence of Brij 35 and then the absorption band decreases with the presence of Brij 35 and further decreases when the concentration of Brij 35 increases (Fig.6).

Our investigations were supported by $\beta$-carotene absorbance in presence of AOT/solvent/water systems at $25^{\circ} \mathrm{C}$ by UV-vis technique [10] in which the solvents selected were: n-heptane, cyclohexane, and tetrahydrofuran and the concentrations of AOT [Aerosol-OT (sodium bis(2-ethylhexyl) sulfosuccinate)] were varied from 0.01 to $0.2 \mathrm{~mol} / \mathrm{kg}$. 
A. Bhattarai et al. / BIBECHANA 11(1) (2014) 40-45: (Online Publication: March, 2014) p.43

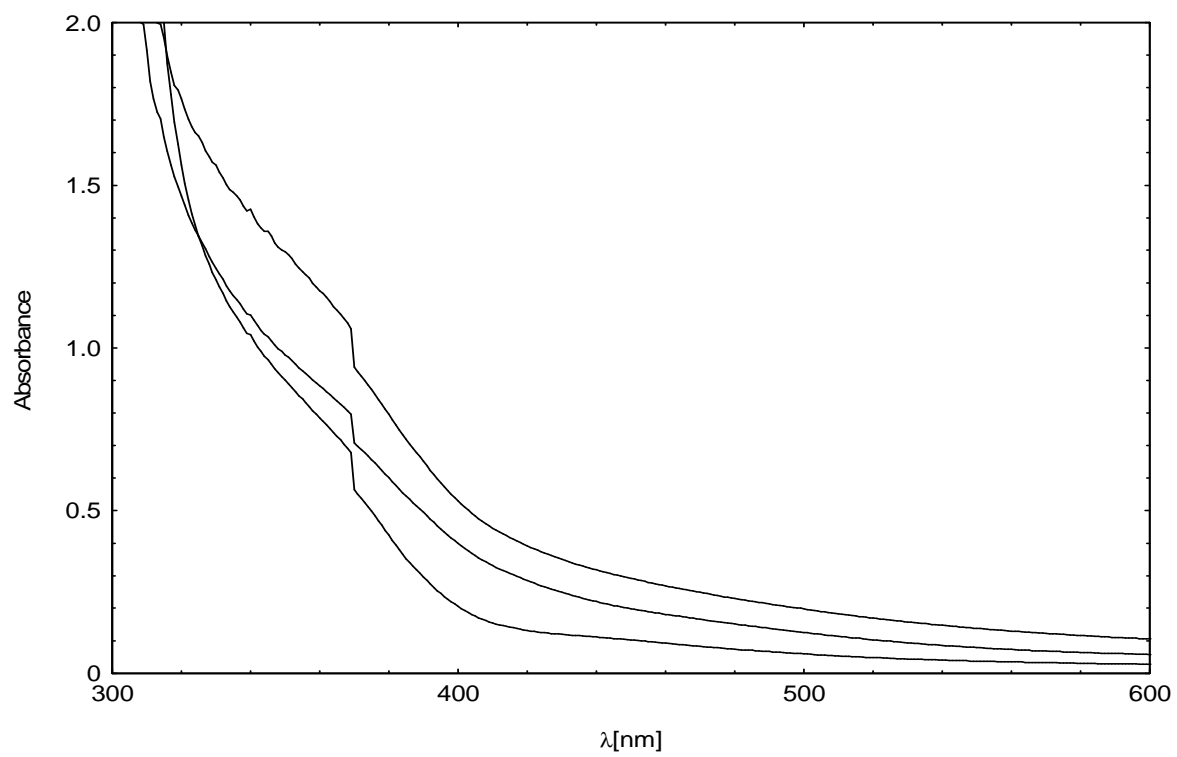

Figure 3: Absorption spectra for 250 micro litre of Orthodox tea in 3ml stock Brij 35 (top graph), 250 micro litre of CTC tea in $3 \mathrm{ml}$ stock Brij 35 (middle graph) and 250 micro litre of Green tea in $3 \mathrm{ml}$ stock Brij 35 (bottom graph).

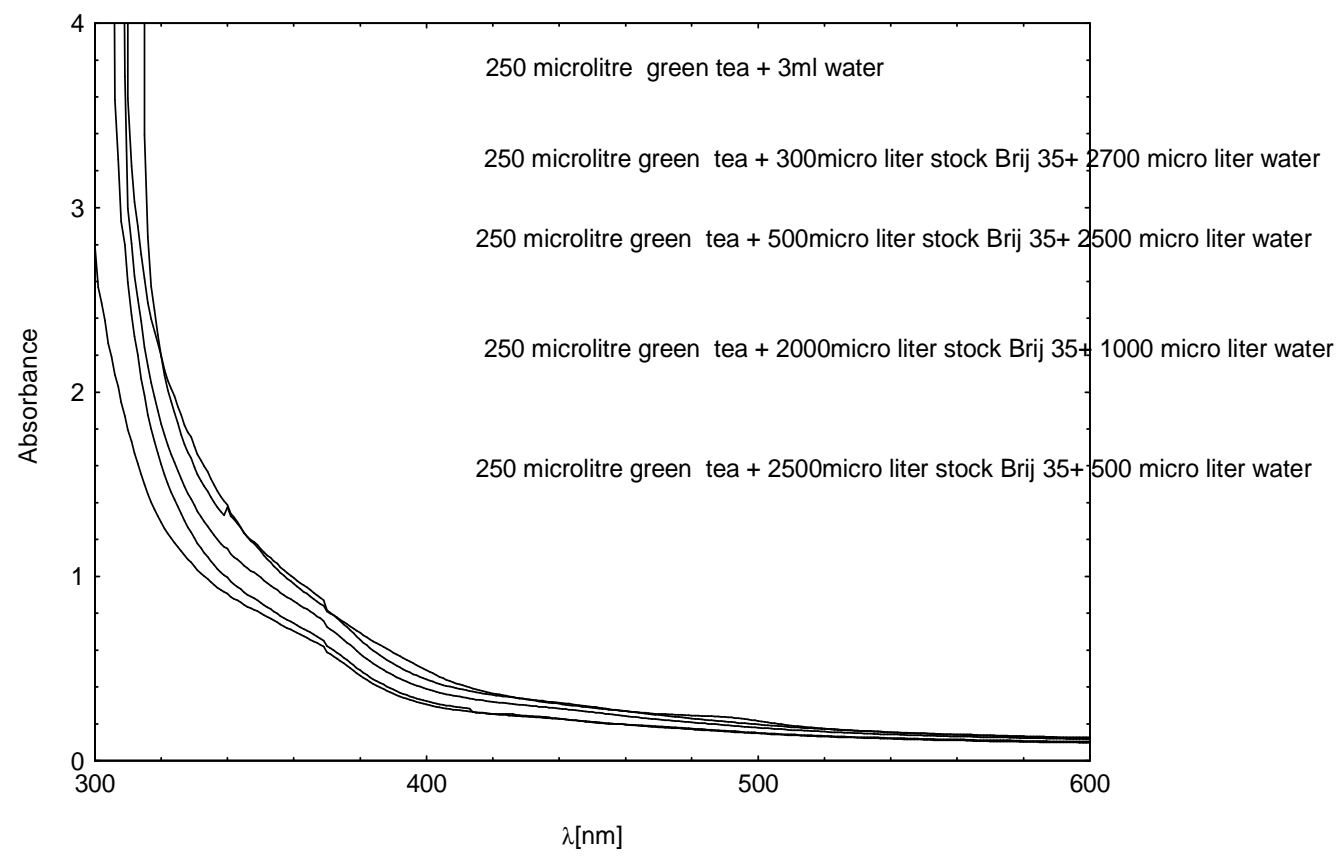

Figure 4: Absorption spectra for 250 micro litre of green tea in $3 \mathrm{ml}$ stock Brij 35 (top graph), and different concentrations of Brij 35 solution in water with 250 micro litre of green tea. 
A. Bhattarai et al. / BIBECHANA 11(1) (2014) 40-45: (Online Publication: March, 2014) p.44

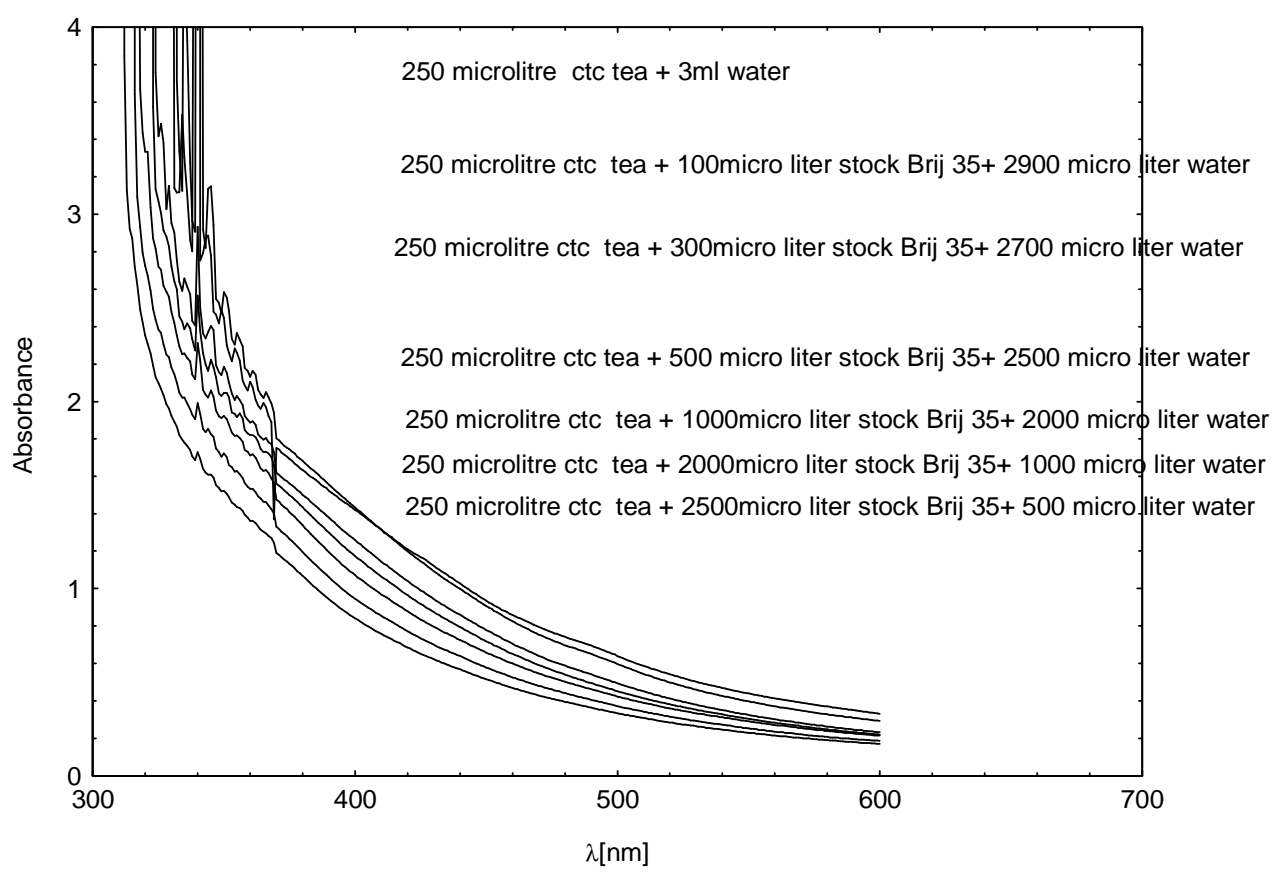

Figure 5: Absorption spectra for 250 micro litre of ctc tea in $3 \mathrm{ml}$ stock Brij 35 (top graph), and different concentrations of Brij 35 solution in water with 250 micro litre of ctc tea.

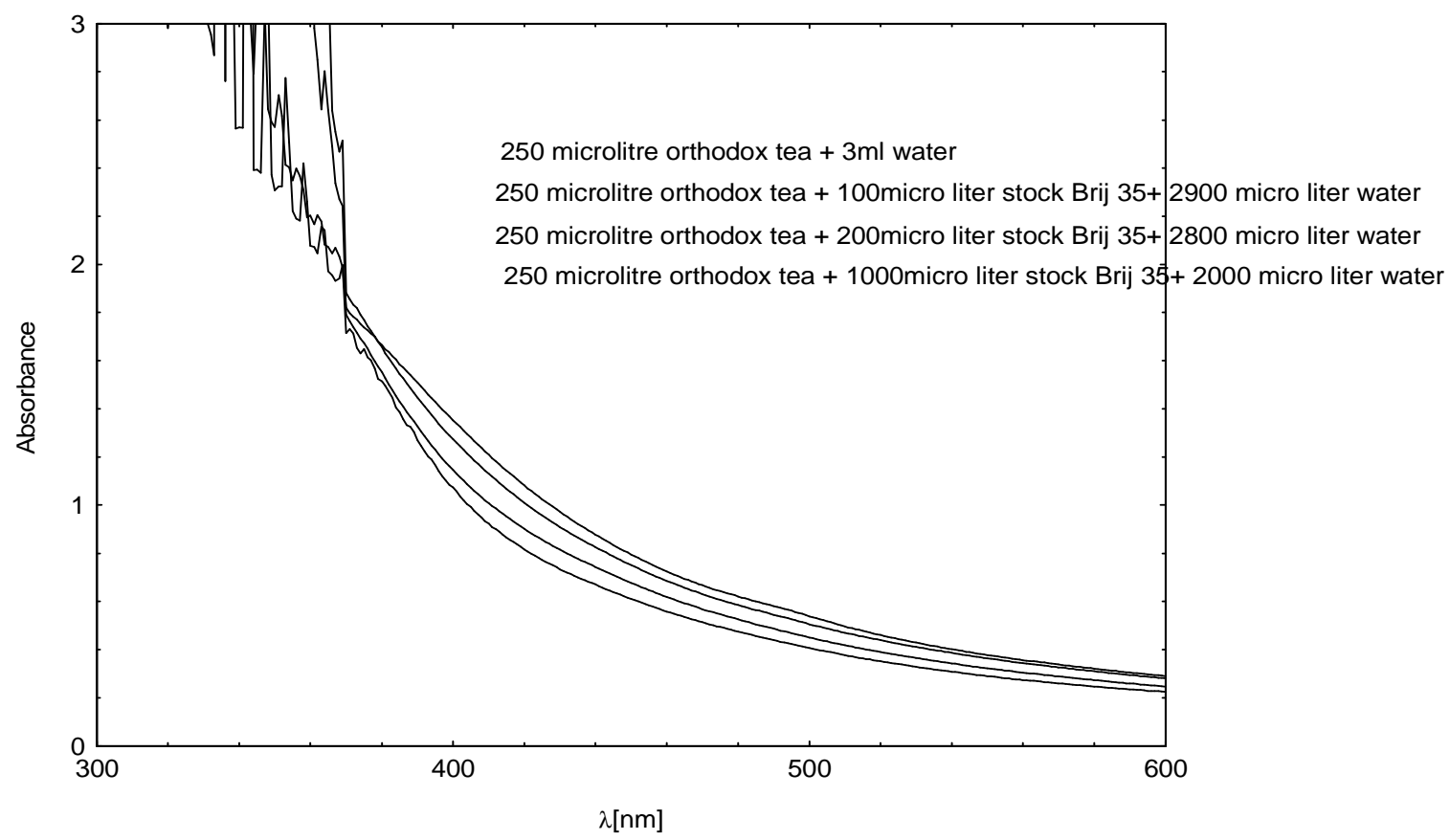

Figure 6: Absorption spectra for 250 micro litre of orthodox tea in $3 \mathrm{ml}$ stock Brij 35 (top graph), and different concentrations of Brij 35 solution in water with 250 micro litre of orthodox tea. 


\section{Conclusion}

Experimental results for the UV-vis measurement of (CTC/Orthodox/Green) Tea in presence of Brij 35/ water at room temperature have been presented as a function of Brij 35 concentration and wave lengths. It was found the highest absorbance was observed for Orthodox tea, lower for CTC tea and the lowest for Green tea. The highest absorbance was noted for Orthodox tea in water with Brij 35 concentration in comparison to CTC tea and Green tea. In all investigated systems, the intensity of (CTC/Orthodox/Green) Tea absorption bands decreases with Brij 35 concentration increasing. This behaviour suggests that (CTC/Orthodox/Green) Tea molecules dipper penetrate into Brij 35.

\section{Acknowledgments}

The authors are thankful to the Campus Chief of Mechi Multiple Campus, Tribhuvan University, Bhadrapur, Nepal for providing us the research facilities to conduct this research work.

\section{References}

[1] D. M. Cacic, M. S. Bosnar, Int. J. Electrochem. Sci., 6 (2011) 1630.

[2] L. Cheng, Handbook of Surfactant Application, Beijing: Beijing Polytechnic University Press, 1994.

[3] N. Arnaud, J.Georges, Spectrochim Acta A Mol. Biomol. Spectrosc., 57A (2001) 1085.

[4] M. Rukhadze , D. Dzidziguri, N. Giorgobiani, S. Kerkenjia, Biomed Chromatogr., 25 (2011) 1364.

[5] C. D. Tran, S. Yu, J. Colloid Interface Sci., 283 (2005) 613.

[6] A. Macfarlane, I. Macfarlane, The Empire of Tea, The Overlook Press, 2004.

[7] P. Ody, Complete Guide to Medicinal Herbs. New York, NY: Dorling Kindersley Publishing, 2000.

[8] M. L. Heiss, R. J. Heiss, The Story of Tea: A Cultural History and Drinking Guide. Random House, 2011.

[9] U. Heinrich, C. E. Moore, S. D. Spirt, H. Tronnier, W. Stahl, J. Nutr., 141 (2011) 1202.

[10] A. Bhattarai, H. Wilczura-Wachnik, J. Applied Sol. Chem. \& Model., 2 (2013) 253. 